\title{
POLÍTICA EUROPEA DE CONTROL DE LAS EXPORTACIONES DE ARMAS CONVENCIONALES Y SEGURIDAD HUMANA: MECANISMOS PARA FOMENTAR EL RESPETO DE LOS DERECHOS HUMANOS *
}

\author{
Joan David JANER TORRENS \\ Profesor titular de Derecho internacional público \\ Universidad de las Illes Balears
}

SUMARIO: 1. INTRODUCCIÓN.-2. LA PROGRESIVA RELEVANCIA DE LOS DERECHOS HUMANOS EN LA NORMATIVA EUROPEA SOBRE COMERCIO DE ARMAS.-3. COOPERACIÓN AL DESARROLLO, TRÁFICO DE ARMAS Y DERECHOS HUMANOS.-4. EL CRITERIO HUMANITARIO Y EL DESARROLLO DE ACTUACIONES EN TERCEROS PAÍSES.- 5. LOS EMBARGOS DE ARMAS ADOPTADOS DE FORMA AUTÓNOMA POR LA UNIÓN EUROPEA COMO VÍA PARA PREVENIR LAS VIOLACIONES DE LOS DERECHOS HUMANOS.-6. DE LA TEORÍA A LA PRÁCTICA: LA APLICACIÓN DEL CRITERIO HUMANITARIO POR ESPAÑA.-7. CONSIDERACIONES FINALES.

\section{INTRODUCCIÓN}

El pasado 2 de abril de 2014, España depositó en la sede Naciones Unidas en Nueva York el instrumento de ratificación del Tratado sobre el Comercio de Armas (TCA) aprobado justo un año antes por la Asamblea General de Naciones Unidas (AGNU) a través de la Resolución 67/234B ${ }^{1}$. Este Tratado

* El presente estudio se ha realizado en el marco del proyecto DER 2012-35049/JURI subvencionado por el Ministerio de Economía y Competitividad.

1 El Consejo de Ministros celebrado el 31 de mayo de 2013 autorizó la firma y la aplicación provisional de los arts. 6 y 7 de dicho Tratado (Aplicación provisional del Tratado sobre Comercio de Armas, hecho en Nueva York el 2 de abril de 2013, en BOE núm. 163, de 9 de julio de 2013). El 20 de febrero de 2014, por 313 votos a favor y una abstención, el Congreso de los Diputados aprobó la ratificación 
supone un paso fundamental en la regulación de las transferencias de armas en la medida en que por primera vez se establecen, como señala el art. 1 de dicho Tratado, «normas internacionales comunes lo más estrictas posible para regular o mejorar la regulación del comercio internacional de armas convencionales» para "prevenir el tráfico ilícito de armas convenciones y prevenir su desvío» y ello con el objetivo de «contribuir a la paz, la seguridad y la estabilidad en el ámbito regional e internacional», "reducir el sufrimiento humano" y "promover la cooperación, la transparencia y la actuación responsable de los Estados parte en el comercio internacional de armas convencionales, fomentando así la confianza entre ellos» ${ }^{2}$.

Hasta el momento, no existía un tratado que regulase el comercio mundial de armas convencionales (incluidas municiones, piezas y componentes) lo cual ha incidido, como señala Naciones Unidas, en el hecho de que "[...] too many weapons are misused or are diverted to unlawful owners, and too often an arms export request denied by one country will be approved by another» ${ }^{3}$. Las manifestaciones de una falta de regulación global del comercio de armas se traducen, según Naciones Unidas, en la muerte de personas y en la comisión de violaciones del Derecho internacional humanitario y de los derechos humanos, en el desplazamiento de personas dentro y fuera de sus fronteras y en el padecimiento de inseguridad y de apuros económicos de aquellas personas afectadas por los conflictos y la violencia armada ${ }^{4}$. Así pues, las consecuencias que para la seguridad humana (entendida esta como el derecho de las personas a vivir de forma segura ${ }^{5}$ tiene la falta de una regulación del tráfico de armas son enormes, pues esta exige protección de las

de dicho Tratado (Diario de Sesiones del Congreso de los Diputados, Pleno y Diputación Permanente, X Legislatura, núm. 179, de 20 de febrero de 2014). El TCA, conforme a lo dispuesto en su art. 22, entró en vigor el 24 de diciembre de 2014. De un total de 130 Estados signatarios, 73 lo han ratificado, lo cual ha permitido su entrada en vigor (United Nations Treaty Collection: web consultada el 8 de septiembre de 2015).

${ }^{2}$ Como pone de manifiesto el centro de investigación Small Arms Survey (www.smallarmssurvey. org), el comercio internacional de armas convencionales es un negocio muy lucrativo que mueve cada año al menos 70.000 millones de dólares y casi un millón de los ocho millones de armas que se producen cada día en el mundo se pierde o es robado, terminando con frecuencia en manos inadecuadas. Cada minuto muere en el mundo una persona a causa de la violencia armada. Se calcula, asimismo, que en el mundo circulan 875 millones o más de armas.

${ }^{3}$ The Impact of Poorly Regulated Arms Transfers on the Work of the United Nations. United Nations coordinating action on small arms (CASA), UNODA Occasional Papers, marzo de 2013, núm. 23 , p. 2.

4 Ibid.

5 El concepto de «seguridad humana» fue acunado por primera por el Programa de Naciones Unidas para el Desarrollo (PNUD) en su Informe de 1994 titulado «Nuevas dimensiones de la seguridad humana” y en él se alude a las distintas amenazas que afectan no a los Estados, sino a las personas vinculándose dicha seguridad al derecho de las personas a vivir libres de temores y de carencias. En este sentido, el Informe estableció siete dimensiones que forman parte de la seguridad humana: económica (disponibilidad de ingresos básicos), alimentaria (disponibilidad de alimentos), en salud (entorno en condiciones de salubridad), medioambiental (equilibrio ecológico), personal (ausencia de violencia física), comunitaria (protección dada por la comunidad, familia o grupo étnico) y política (respeto a los derechos fundamentales). Sobre esta cuestión, y sin ánimo de exhaustividad, véase PÉREZ DE ARMINo, K. y Mendia AzKue, M. (eds.), Seguridad humana. Aportes cr ticos al debate te rico y pol tico, Madrid, Tecnos, 2013. Véase también, MARRERo Rocha, I., «El régimen de control de comercio de armas convencionales y su contribución a la seguridad internacional», en BouZa VIDAL, N., GARcía SEGURA, C. y 
personas contra la violencia y contra la amenaza de violencia ${ }^{6}$ y, de ahí, la necesidad y oportunidad de dotarse de un instrumento jurídicamente vinculante como el TCA.

Uno de los aspectos más relevantes que tiene el comercio de armas es el relativo a los efectos que su tráfico incontrolado puede tener sobre los derechos humanos de la población en la medida en que estas se pueden utilizar contra la sociedad civil. El TCA alude claramente a esta cuestión por partida doble. Por una parte, el art. 6.3 prohíbe de forma taxativa a los Estados que autoricen cualquier tipo de transferencia de armas convencionales cuando tengan conocimiento de que las armas "podrían utilizarse para cometer genocidio, crímenes de lesa humanidad, infracciones graves de los Convenios de Ginebra de 1949, ataques dirigidos contra bienes de carácter civil o personas civiles protegidas, $\mathrm{u}$ otros crímenes de guerra tipificados en los acuerdos internacionales en los que sea parte». Por otra parte, en caso de que una exportación de armas no esté prohibida, el art. 7 prevé que los Estados podrán no conceder licencias de exportación si las armas pudiesen servir para «cometer o facilitar una violación grave del Derecho internacional humanitario» o para «cometer o facilitar una violación grave del Derecho internacional de los derechos humanos» ${ }^{7}$.

La inclusión del criterio humanitario, recogido en los arts. 6 y 7 del TCA, como parámetro restrictivo o limitativo a las transferencias internacionales de armamentos, vinculándose este a la violación del Derecho Internacional de los Derechos Humanos (DIDH), del Derecho Internacional Humanitario (DIH) o a la comisión de alguno de los crímenes más graves de transcendencia internacional, supone la introducción de un parámetro muy relevante en el comercio mundial de armas, el cual tuvo un amplio respaldo de los diferentes países que participaron en la elaboración del TCA ${ }^{8}$. La finalidad de la inserción del criterio humanitario en el TCA «[...] no es punitiva, es decir, de sanción frente a prácticas precedentes de violación de los derechos humanos y/o del DIDH, sino preventiva, orientada a evitar o minimizar el riesgo de violaciones futuras tratando de impedir que el posible responsable llegue a contar con los medios para cometerlas» ${ }^{9}$.

Rodrigo Hernández, A. R. (dirs.); Pareja Alcaraz, P. (coord.), La Gobernanza del interés público global. Actas de las XXV Jornadas de la AEPDIRI, Madrid, Tecnos, 2015, pp. 287-312.

${ }^{6}$ En este sentido, se ha observado que «[...] lograr la seguridad humana exige mucho más que el desarme, pero si no se empeñan esfuerzos importantes para desarmarse, las iniciativas para afianzar la seguridad humana serán, casi con certeza, incompletas. Es poco probable que una comunidad inundada de armas ilícitas sea un lugar seguro para las personas». Véase GILlis, M., Desarme: Guía básica, Nueva York, 3. ${ }^{\mathrm{a}}$ ed., Oficina de las Naciones Unidas para Asuntos de Desarme, 2013, p. 6.

7 Ante la falta de concreción por el TCA de qué debe considerarse una «violación grave del Derecho internacional de los derechos humanos», recientemente se ha publicado un estudio que pretende precisar dicho concepto. Véase Karimova, T., "What Amounts to "a Serious Violation of International Human Rights Law"? An Analysis of Practice and Expert Opinion for the Purpose of the 2013 Arms Trade Treaty», Geneva Academy Briefing, agosto de 2014, núm. 6.

8 Sobre esta cuestión, véase SÁnCHEz LEgIDo, A., Hacia una regulación global del comercio internacional de armas, Valencia, Tirant lo Blanch, 2014, especialmente pp. 165-181.

9 Ibid., p. 175. 
En la medida en que el TCA tiene una clara incidencia en cuestiones que son de competencia exclusiva de la Unión Europea (UE) al entrar en el ámbito de la política comercial común o de las normas del mercado interior aplicables a la transferencia de armas convencionales y explosivos, el 3 de marzo de 2014, el Consejo adoptó una Decisión por la que se autorizaba a los Estados miembros a ratificarlo, en interés de la UE, pues solo los Estados miembros pueden ser partes ${ }^{10}$. El hecho de que los Estados miembros de la UE, en su conjunto, sean el principal exportador de armas en el mundo, por delante de los Estados Unidos y Rusia y que, en 2011, el porcentaje de estas exportaciones destinadas a terceros países aumentase un 61 por 100 , pone de relieve la importancia que tiene la ratificación del TCA ${ }^{11}$.

La inclusión del criterio humanitario en el TCA entra claramente en coherencia con la promoción de los derechos humanos como principio que informa la acción exterior de la UE (art. 3.5 del TUE) y, de forma particular, su política comercial. En todo caso, el criterio humanitario no constituye una novedad en relación con la política europea de exportación de armas convencionales, pues desde 1998 existen distintas disposiciones que dotan de contenido a esta prohibición. Asimismo, los Estados miembros de la UE, y particularmente España ${ }^{12}$, han adoptado distintas disposiciones legales y reglamentarias para prohibir la venta de armas convencionales a países que las puedan utilizar contra la población. Esta prohibición también se ha materializado en la adopción de medidas restrictivas de tipo autónomo (no adoptadas al amparo de resoluciones del Consejo de Seguridad de Naciones Unidas) por parte de la UE contra terceros países, que incluyen la prohibición de que los Estados miembros vendan armas que «puedan utilizarse con fines de represión interna».

Partiendo del análisis de la incorporación del criterio humanitario con anterioridad a la entrada en vigor del TCA en la normativa europea de exportación de armas y su proyección en las legislaciones nacionales (especialmente, España), este estudio pretende analizar distintos instrumentos de política exterior (como la cooperación al desarrollo o los embargos decretados de forma unilateral) que ha utilizado la UE para evitar que las armas que los Estados miembros vendan a terceros países puedan ser utilizadas contra la población civil, valorándose en último término la práctica desarrollada por España en materia de venta de armas en relación con la observancia del criterio humanitario.

10 DO L núm. 89, de 25 de marzo de 2014. Previamente, el 27 de mayo de 2013, el Consejo había adoptado la Decisión 2013/269/PESC por la que se autorizaba a los Estados miembros a firmar, en interés de la Unión Europea, el TCA (DO L núm. 155, de 7 de junio de 2013).

11 Estos datos figuran en la «Propuesta de Resolución del Parlamento Europeo, de 5 de junio de 2013 sobre las exportaciones de armamento: aplicación de la Posición común 2008/944/PESC del Consejo", Doc. B7-0258/2013, p. 4.

12 Según el Stockholm International Peace Research Institute (SIPRI), durante el periodo 20102014, España se ha situado en el séptimo lugar en la lista de los países exportadores de armas. Alemania ocupa el cuarto lugar, Francia el quinto y el Reino Unido el sexto lugar. Véase SIPRI Yearbook 2015: Armaments, Disarmament and International Security, p. 17. 


\section{LA PROGRESIVA RELEVANCIA DE LOS DERECHOS HUMANOS EN LA NORMATIVA EUROPEA SOBRE COMERCIO DE ARMAS}

Las primeras referencias en el ámbito europeo al respeto de los derechos humanos como factor a tener en cuenta en el comercio de armas se remontan, a pesar de la ausencia de una referencia expresa a la dimensión externa de los derechos humanos en la acción exterior de la Unión ${ }^{13}$, a la aprobación por el Consejo de Asuntos Generales celebrado el 25 de mayo de 1998 del Código de Conducta en materia de exportación de armas ${ }^{14}$. Si bien se trataba de un acuerdo de naturaleza política y, por tanto, no vinculante para los Esta$\operatorname{dos}^{15}$, estos, conforme al segundo criterio recogido en el código de conducta, identificaban el respeto de los derechos humanos en el país de destino final de las armas como motivo para no expedir licencias de exportación. El Código de Conducta vinculaba dicho respeto con la posibilidad de que las armas pudiesen ser utilizadas «con fines de represión interna».

A partir de la entrada en vigor, en 1999, del Tratado de Ámsterdam que supuso dotar de una mayor relevancia a los derechos humanos tanto en el propio seno de la Unión como en su acción exterior ${ }^{16}$, la UE fue adoptando distintas disposiciones en materia de comercio tanto interno como externo de armas en las cuales se hacía referencia a los derechos humanos como un límite en la concesión de licencias de exportación, lo cual tuvo el efecto de que esta cuestión se incorporase en las legislaciones nacionales en materia de venta de armamento.

Si bien en 1994 se reguló por primera vez el sistema de control de las exportaciones de productos de doble uso ${ }^{17}$ a través del Reglamento 3381/94,

${ }^{13}$ Cabe recordar que el Tribunal de Justicia de la UE había reconocido que los derechos humanos fundamentales formaban parte de los principios generales del Derecho que derivaban de las tradiciones constitucionales de los Estados miembros y de los principales instrumentos internacionales y regionales de defensa de los derechos humanos.

14 Sesión núm. 2097 del Consejo, Doc. 8687/98, de 25 de mayo. Este Código de Conducta tomaba como referencia la Declaración del Consejo Europeo de 28 y 29 de junio de 1991 celebrado en Luxemburgo sobre la no proliferación y la exportación de armas, en la cual se constataba que «el respeto de los derechos humanos en el país de destino» se hallaba recogido en distintas legislaciones nacionales sobre exportación de armas y planteaba que este criterio, junto a otros, figurase como elemento a tener en cuenta en la armonización de las políticas nacionales en esta materia. Véase Anexo VII de las Conclusiones, Doc. SN 151/3/91 REV 3, pp. 31 y 32.

15 En relación con el Código de Conducta, Jaume Ferrer Lloret observó que «[...] se trata de un acuerdo político (no publicado en el DOCE) cuya naturaleza jurídica está sometida al Derecho internacional público y en particular al principio de la buena fe en su cumplimiento, a través siempre de los ordenamientos internos de los Estados miembros». Véase FERRER LLORET, J., «La aplicación de medidas de embargo de armas adoptadas por la Unión Europea», RDCE, vol. 6, 1999, p. 286.

16 Véase McGoldRick, D., «The European Union after Amsterdam: an Organization with General Human Rights Competence?», en Twomey, P. y O'KeEfFE, D. (eds.), Legal Issues of the Amsterdam Treaty, Londres, Hart Publishing, 1999, pp. 249-270. Recientemente, la Comisión Europea y la Alta Representante de la Unión para Asuntos Exteriores y Política de Seguridad han reafirmado el compromiso de la UE con los derechos humanos tanto en su acción exterior como en sus políticas y en sus relaciones con la sociedad civil. Véase «Comunicación conjunta al Parlamento Europeo y al Consejo: Plan de Acción Conjunto sobre Derechos Humanos y Democracia», JOIN (2015) 16 final, de 28 de abril.

17 Se entiende por productos de doble uso aquellos productos, incluidos el soporte lógico (software) y la tecnología, que pueden destinarse a usos tanto civiles como militares o usos nucleares. 
de 19 de diciembre ${ }^{18}$, no fue hasta la nueva regulación hecha por el Reglamento 1334/2000, de 22 de junio, por el que se establece un régimen comunitario de control de las exportaciones de productos y tecnología de doble uso ${ }^{19}$ cuando se hizo alusión en su art. 5.1 a «consideraciones sobre derechos humanos» como motivo que permitía a los Estados prohibir la exportación de este tipo de productos. Aunque se trataba de una referencia muy genérica y no se precisaba qué debía entenderse por este tipo de consideraciones, lo cierto es que, de forma muy novedosa y al hilo del nuevo marco en materia de derechos humanos introducido por el Tratado de Ámsterdam, los Estados podían prohibir la exportación de este tipo de productos si consideraban que se podían utilizar para vulnerar los derechos humanos. En el caso español, la Ley 53/2007, de 28 de diciembre, sobre el control del comercio exterior de material de defensa y doble uso ${ }^{20}$, en línea con lo dispuesto en el Reglamento $1334 / 2000$, tuvo el mérito de precisar que los derechos humanos operaban como límite a la transferencia de material de doble uso de tal manera que las autoridades encargadas de expedir las licencias de exportación tenían un criterio más definido a la hora de conceder o denegar las correspondientes autorizaciones $^{21}$.

A partir de 2003, y vinculado al diseño de la Estrategia Europea de Seguridad, se produce un claro reconocimiento de los derechos humanos como elemento a tener en cuenta en la exportación de armas. En efecto, si bien es cierto que la Estrategia Europea de Seguridad (EES), aprobada el 13 de diciembre de 2003, no aludía de forma específica al comercio incontrolado de armas convencionales ${ }^{22}$ como uno de los retos que pueden amenazar la seguridad europea, cabe señalar que las consecuencias de la fabricación, transferencia y circulación ilícitas de armas pequeñas y ligeras, así como su acumulación excesiva y su diseminación incontrolada, están en la raíz de cuatro de los cinco retos definidos (terrorismo, proliferación armas de destrucción masiva, conflictos regionales, descomposición de los Estados y delincuencia

18 DO L núm. 367, de 31 de diciembre de 1994.

19 DO L núm. 159, de 30 de junio de 2000.

20 BOE núm. 312, de 29 de diciembre de 2007.

21 Así, el art. 8.1.a) señala que las solicitudes de autorización serán denegadas, suspendidas o revocadas «cuando existan indicios racionales de que el material de defensa, el otro material o los productos y tecnologías de doble uso puedan ser empleados en acciones que perturben la paz, la estabilidad o la seguridad en un ámbito mundial o regional, puedan exacerbar tensiones o conflictos latentes, puedan ser utilizados de manera contraria al respeto debido y la dignidad inherente al ser humano, con fines de represión interna o en situaciones de violación de los derechos humanos, tengan como destino países con evidencia de desvíos de materiales transferidos o puedan vulnerar los compromisos internacionales contraídos por España». El contenido de este precepto se reitera en el art. 7.1.a) del Real Decreto 2061/2008, de 12 de diciembre, por el que se aprueba el Reglamento de control de comercio exterior de material de defensa, de otro material y de productos y tecnologías de doble uso (BOE núm. 6, de 7 de enero de 2009). Este Real Decreto fue modificado posteriormente por el Real Decreto 844/2011, de 17 de junio, sin que se introdujesen novedades significativas en este ámbito (BOE núm. 157, de 2 de julio de 2011).

${ }^{22} \mathrm{El}$ art. 2 del TCA enumera las distintas armas convencionales: carros de combate, vehículos blindados de combate, sistemas de artillería de gran calibre, aeronaves de combate, helicópteros de ataque, buques de guerra, misiles y lanzamisiles y armas pequeñas y ligeras. 
organizada) en la EES. Sobre esta base, se aprobaron distintos instrumentos de política exterior dirigidos a que los Estados controlasen el comercio de armas pequeñas y ligeras, así como las exportaciones de tecnología y equipos militares.

De forma implícita, la Estrategia de la UE contra la acumulación y el tráfico ilícito de armas pequeñas y ligeras y de sus municiones aprobada por el Consejo Europeo en diciembre de $2005^{23}$ aludía a las consecuencias que, en términos de violaciones de derechos humanos por su vinculación con el terrorismo y la delincuencia organizada ${ }^{24}$, tenía la falta de control del tráfico ilícito de armas pequeñas y ligeras y, de ahí, la necesidad de que la UE adoptase una estrategia en este ámbito con efectos ad intra (políticas de la UE) como ad extra (Naciones Unidas, políticas dirigidas a regiones concretas y diálogos estructurados con países). Este documento era más bien de carácter programático y no se imponían obligaciones a los Estados miembros ${ }^{25}$. En todo caso, la relación entre derechos humanos, comercio incontrolado de armas y seguridad interna planteaba la necesidad de algún tipo de actuación en este ámbito por parte de la UE en la medida en que el propio art. 3 del TUE alude a la seguridad tanto interna como internacional y a la protección de los derechos humanos como objetivos a perseguir por la Unión ${ }^{26}$.

Las referencias a las violaciones de los derechos humanos como factor a tener en cuenta a la hora de conceder licencias de exportación por parte de los Estados, sí fueron reconocidas de forma explícita en la Posición común 2008/944/PESC del Consejo, de 8 de diciembre, por la que se definen las normas comunes que rigen el control de las exportaciones de tecnología y equipos militares, ámbito que continúa siendo competencia de los Estados miembros ${ }^{27}$. Después de aludir en la exposición de motivos a la resolución de los Estados de «evitar la exportación de tecnología y equipos militares que pudieran utilizarse para la represión interna o la agresión internacional o contribuir a la inestabilidad regional», la Posición común fijaba ocho

23 Doc. 5319/06, de 13 de enero de 2006.

24 El punto 11 de la Estrategia señalaba que «al margen de los efectos humanitarios, las consecuencias que para el desarrollo de los países afectados están bien documentadas: debilitamiento de las estructuras del Estado, desplazamiento de personas, desmoronamiento de los servicios sanitarios y educativos, declive de la actividad económica, reducción de los recursos del Estado, propagación de pandemias y daños al tejido social, que dan lugar a largo plazo a la reducción o la retirada de la ayuda para el desarrollo».

${ }_{25}$ Con anterioridad, se había adoptado la Acción común del Consejo, de 12 de julio de 2002, sobre la contribución de la Unión Europea para combatir la acumulación desestabilizadora y la proliferación de armas ligeras y de pequeño calibre, y por la que se deroga la Acción común 1999/34/PESC (DO L núm. 191, de 19 de julio de 2002) en la cual se aludía a los efectos «desestabilizadores» y a «los problemas causados» por la acumulación de este tipo de armas, pero no había ninguna mención expresa a los efectos que ello podía tener sobre los derechos humanos.

${ }_{26} \mathrm{Si}$ bien este estudio se centra en las exportaciones de armas a terceros países y, por tanto, en la dimensión exterior de la seguridad, cabe señalar que el tráfico incontrolado de armas de fuego también afecta a la seguridad interna de la propia UE. Véase la «Comunicación de la Comisión al Consejo: las armas de fuego y la seguridad interna de la UE: proteger a los ciudadanos e impedir el tráfico ilícito y al Parlamento Europeo», COM (2013) 716 final, de 21 de octubre.

27 DO L núm. 335, de 13 de diciembre de 2008. 
criterios que debían tener en cuenta los Estados a la hora de aprobar las solicitudes de licencias de exportación de armas. El segundo criterio se refería al «respeto de los derechos humanos en el país de destino final [de la tecnología y equipos militares] y respeto del Derecho internacional humanitario por parte de dicho país». Curiosamente, en dos supuestos se establecía la obligación de los Estados de denegar las licencias de exportación (en caso de que las armas pudiesen ser utilizadas con fines de represión interna o si existía riesgo manifiesto de que la tecnología y equipos militares pudiese usarse para cometer violaciones graves del DIH) y, en otro, solo se imponía a los Estados la necesidad de ponderar «con especial detenimiento y vigilancia la concesión de licencias» a los países en los que Naciones Unidas, la UE o el Consejo de Europa hubiesen constatado «graves violaciones de los derechos humanos» ${ }^{28}$. Cabe destacar también que el art. 10 de la Posición común permitía a los Estados tener en cuenta el efecto de las exportaciones de armas en sus propios intereses económicos, sociales, comerciales e industriales, pero estos en ningún caso debían afectar la aplicación de los ocho criterios, lo cual suponía darles prioridad a la hora de conceder licencias de exportación ${ }^{29}$.

Con el objetivo de facilitar la aplicación de los criterios establecidos en la Posición común 2008/944/PESC, el Consejo aprobó el 29 de abril de 2009 una Guía de Usuario de dicha posición común que contenía una serie de pautas que debían guiar a los Estados a la hora de conceder licencias de exportación de $\operatorname{armas}^{30}$. La Guía del usuario recoge lo dispuesto en el Código de Conducta en materia de exportación de armas aprobado por el Consejo de Asuntos Generales en 1998 al que ya se ha aludido y define claramente qué deberá entenderse por represión interna, lo cual introduce una dosis de certeza muy relevante a la hora de conceder licencias mientras que, en relación con lo que se puede considerar violaciones graves del DIH y graves violaciones de los derechos humanos, estas serán valoradas por cada Estado según su criterio a partir de una serie de indicadores como, entre otros, la ratificación por el Estado destinatario de las exportaciones de tratados en materia de derechos humanos y de derecho humanitario, la adopción por dicho Estado de normas y prácticas internas en materia de derechos humanos, la eventual participa-

28 Esa ponderación puede implicar, como ha señalado Eduardo Melero Alonso, que se autoricen las exportaciones a países en los que se han constatado graves violaciones de los derechos humanos, pero dicha autorización solo será factible si existe «un interés de enorme peso en el sentido favorable a la exportación», siendo también necesaria que la Administración «motive de forma especialmente intensa su decisión». Véase Melero Alonso, E., «La Posición Común 2008/944/PESC sobre control de las exportaciones de tecnología y equipos militares: análisis crítico», REDE, 2010, núm. 34, p. 254.

29 Bosnia y Herzegovina, la Antigua República Yugoslava de Macedonia, Islandia, Canadá, Montenegro y Noruega han asumido oficialmente los criterios y principios establecidos en la Posición Común y, desde 2012, está en vigor un sistema de intercambio de información entre la UE y estos países sobre exportación de armas. Véase «Decimoquinto informe anual realizado con arreglo al art. 8, apartado 2 de la Posición común 2008/944/PESC», DO C núm. 18, de 21 de enero de 2014, p. 1.

30 "Guía del usuario de la Posición común 2008/944/PESC del Consejo por la que se definen las normas comunes que rigen el control de las exportaciones de tecnología y equipos militares», Doc. 9241/09, de 29 de abril de 2009. Véase Bromley, M. y BRzosKA, M., «Towards a Common, Restrictive EU Arms Export Policy? The Impact of the EU Code of Conduct on Major Conventional Arms Exports?», European Foreing Affairs Review, vol. 13, 2008, núm. 3, pp. 333-356. 
ción de dicho Estado en violaciones de derechos humanos, colaboración y cooperación con tribunales especiales o con la Corte Penal Internacional o al adiestramiento de la fuerzas armadas del Estado receptor en materia de derechos humanos.

Así pues, desde 2008, los 28 Estados miembros de la UE, conforme al segundo criterio de la Posición común 2008/944/PESC, el cual, según el art. 10 de la misma, debe prevalecer sobre los «intereses económicos, sociales, comerciales e industriales» de los Estados, deben denegar, si bien su incumplimiento no tiene consecuencias jurídicas, las licencias de exportación de tecnología y equipos militares si este material se puede utilizar con fines de represión interna, para llevar a cabo violaciones de los derechos humanos o para cometer violaciones graves del DIH.

El respeto de los derechos humanos como límite a la transferencia de armamento hacia terceros países se recoge también como un aspecto a tener en cuenta por los Estados en la concesión de licencias, tal y como señala el art. 4.6 de la Directiva 2009/43/CE, del Parlamento Europeo y del Consejo, de 6 de mayo, sobre la simplificación de los términos y las condiciones de las transferencias de productos relacionados con la defensa dentro de la Comunidad $^{31}$. En efecto, a la hora de conceder licencias de exportación de armas dentro de la UE, los Estados podrán establecer «limitaciones de la exportación de productos relacionados con la defensa a personas físicas o jurídicas en terceros países, habida cuenta, entre otras, de los riesgos que la transferencia genera para la preservación de los derechos humanos, la paz, la seguridad y la estabilidad». A diferencia de la Posición común, y si bien la Directiva 2009/43 se centra en el mercado intracomunitario de productos relacionados con la defensa, la referencia expresa a la posibilidad de denegar licencias de exportación en caso de que se tenga constancia de que estos se puedan utilizar para cometer violaciones de los derechos humanos en terceros países constituye, en la medida en que su contenido se debe incorporar necesariamente a la legislación interna, una novedad muy destacable.

En el caso español, la Directiva 2009/43 fue traspuesta a través del Real Decreto 844/2011, de 17 de junio $^{32}$, sin que ello introdujese ningún tipo de modificación sustancial a lo ya previsto (y analizado) en el Real Decreto 2061/2008, de 12 de diciembre, por el que se aprueba el Reglamento de control del comercio exterior de material de defensa, de otro material y de productos y tecnologías de doble uso. La nueva redacción del art. 7.1 del Real Decreto 2061/2008 dada por el Real Decreto 844/2011, de 17 de junio, continuaba prestando especial atención al respeto de los derechos humanos como factor a tener en cuenta a la hora de suspender, denegar o revocar licencias de exportación de armas por parte de la Secretaría de Estado de Comercio.

31 DO L núm. 146, de 10 de junio de 2009. Véase, también, el «Informe de la Comisión al Parlamento europeo y al Consejo sobre la transposición de la Directiva 2009/43/CE sobre la simplificación de los términos y las condiciones de las transferencias de productos relacionados con la defensa dentro de la UE», COM (2012) 359 final, de 29 de junio.

32 BOE núm. 157, de 2 de julio de 2011. 
Actualmente, el Real Decreto 679/2014, de 1 de agosto $^{33}$, que refunde distintos reglamentos sobre comercio exterior de armas y alude directamente a los arts. 6 y 7 del TCA, hace una referencia expresa en su art. 7.1.a) al criterio humanitario a la hora de suspender, denegar o revocar licencias de exportación de material de defensa, de otro material y de productos y tecnologías de doble uso.

\section{COOPERACIÓN AL DESARROLLO, TRÁFICO DE ARMAS Y DERECHOS HUMANOS}

En la medida en que el tráfico ilícito de armas puede ser un factor generador de conflictos donde se vulneren los derechos fundamentales de las personas, la UE ha utilizado distintos instrumentos de política exterior y de cooperación al desarrollo para incidir en esta cuestión. La promoción y respeto de los derechos humanos y la prevención de conflictos figuran entre los distintos objetivos de la acción exterior de la UE [art. 21.b) y c) del TUE] que informan también de la propia ayuda al desarrollo de la Unión (art. 208.1 del TFUE). Un año después de que en 2000 la Asamblea General de Naciones Unidas aprobase la Declaración del Milenio ${ }^{34}$, que aludía a los efectos que tenía el tráfico ilícito de armas pequeñas y ligeras en el mantenimiento de la paz y seguridad mundial ${ }^{35}$, la Comisión Europea publicó una Comunicación relativa a la prevención de conflictos señalando que el tráfico y la utilización de armas eran un factores generadores de $\operatorname{conflictos}^{36}$. Por ello, se abogaba por la integración de la prevención de conflictos (incluidos los armados) en los programas de cooperación al desarrollo de la Unión, cuestión que también fue reconocida en el Consenso Europeo sobre Desarrollo aprobado en $2005^{37}$.

33 BOE núm. 207, de 26 de agosto de 2014.

34 A/RES/55/2, de 13 de septiembre de 2000.

35 El punto II de la Declaración del Milenio llevaba por título «La paz, la seguridad y el desarme» y, entre otros, se hacía especial énfasis en la adopción de medidas concertadas para poner fin al tráfico ilícito de armas pequeñas y ligeras (p. 4).

36 En la «Comunicación de la Comisión relativa a la prevención de conflictos», COM (2001) 211 final, de 11 de abril, p. 19, se señalaba que «[...] las pequeñas armas son las "armas de destrucción masiva” de los pobres. Les son imputables más muertes y heridas y una mayor influencia destructiva en las estructuras políticas y sociales que a cualquier otra categoría de armas. Las pequeñas armas llegan fácilmente a las zonas afectadas por los conflictos y más vulnerables a su impacto. También es en esas zonas donde tienen menos posibilidades de ser sometidas a control jurídico».

37 El punto 37 de dicho documento (Declaración conjunta del Consejo y de los Representantes de los Gobiernos de los Estados miembros reunidos en el seno del Consejo, del Parlamento Europeo y de la Comisión sobre la política de desarrollo de la Unión Europea titulada «El Consenso Europeo sobre Desarrollo», en DO C núm. 46, de 24 de febrero de 2006) señala que «[...] la inseguridad y los conflictos se encuentran entre los principales obstáculos para la consecución de los Objetivos del Milenio [...]. La UE [...] reforzará el control de sus exportaciones de armas para evitar que el armamento fabricado en la UE se emplee contra las poblaciones civiles o sirva para agravar tensiones y conflictos existentes en los países en desarrollo, y adoptará medidas concretas destinadas a limitar la proliferación incontrolada de armas ligeras y de pequeño calibre [...]». En relación con este documento, véase nuestro estudio, «La contribución del Consenso europeo sobre el desarrollo al mantenimiento de la paz y seguridad 
En línea con ello, el establecimiento, mediante el Reglamento 1717/2006, de 15 de noviembre ${ }^{38}$, del llamado "Instrumento de Estabilidad» (IE) constituye una clara materialización de la vinculación existente entre la acción exterior de la UE, la cooperación al desarrollo, el fomento de los derechos humanos, la prevención de conflictos y el control del tráfico de armas. Con cargo al IE (con una vigencia entre 2007 y 2013) se financiaron tanto respuestas de la UE a situaciones de crisis o de crisis incipientes, como distintas medidas dirigidas a controlar aspectos diversos relacionados con el tráfico de armas. En efecto, el art. 1.h) del Reglamento 1717/2006 señalaba que la ayuda técnica y financiera con cargo al IE se podía destinar a «[...] abordar [...] el impacto socioeconómico en la población civil de las minas antipersonas, los artefactos sin explotar o restos de explosivos abandonados, [...] la asistencia a las víctimas, la detección y supresión de minas y, en relación con ello, la destrucción de reservas». Asimismo, según el art. 1.i), el IE también podía servir para abordar «[...] el impacto en la población civil de la adquisición y uso ilícito de armas de fuego [...]». El IE, que expiró en diciembre de 2013, fue sustituido posteriormente, mediante el Reglamento $230 / 2014$, de 11 de marzo $^{39}$, por un nuevo instrumento financiero en materia de cooperación al desarrollo denominado «Instrumento en pro de la estabilidad y la paz» para el periodo 2014-2020. En términos generales, este nuevo instrumento financiero mantiene las líneas de financiación previstas en el IE si bien, desde la perspectiva del control de armas y su incidencia en la prevención de conflictos y en las situaciones de crisis, introduce alguna novedad. Así, cabe señalar que el art. 3.j), en relación con los ámbitos en los cuales se proyectará la ayuda técnica y financiera, alude al «apoyo a las medidas dirigidas a combatir, en el marco de las políticas de cooperación de la Unión y sus objetivos, el uso y acceso ilícitos a las armas de fuego y a las armas ligeras y de pequeño calibre», cuestión a la que no se hacía referencia en el anterior IE.

De esta manera, a través del instrumento financiero que da cobertura a las distintas iniciativas en materia de cooperación al desarrollo, es factible que la UE dé apoyo técnico y financiero a cualquier iniciativa que plantee un país receptor de ayuda al desarrollo dirigida a controlar el uso y acceso ilícito a distintas armas convencionales.

\section{EL CRITERIO HUMANITARIO Y EL DESARROLLO DE ACTUACIONES EN TERCEROS PAÍSES}

A raíz de la aprobación en 1998 del ya analizado Código de Conducta — transformado en 2008 en una Posición común—en materia de exportación

\footnotetext{
mundial», en Huesa VinaIXA, R. (coord.), Derechos humanos, responsabilidad internacional y seguridad colectiva. Intersección de sistemas, Madrid, Marcial Pons, 2008, pp. 143-159.

38 DO L núm. 327, de 24 de noviembre de 2006.

39 DO L núm. 77, de 15 de marzo de 2014.
} 
de armas, en el que se identificaba la falta de respeto de los derechos humanos en el país de destino final de las armas como motivo para no expedir licencias de exportación, la UE adoptó en $2008^{40}, 2009^{41}$ y $2012^{42}$ distintas iniciativas dirigidas a promover que los principios y valores recogidos en dicho acuerdo fueran también tenidos en cuenta por terceros países, tal como figuraba en el art. 11 de la Posición común. De alguna manera, la UE, ante la ausencia de un tratado internacional sobre control de armas que aludiese al respeto a los derechos humanos como límite a las exportaciones de armas, pretendía fomentar los criterios y principios del Código de Conducta mediante la asistencia económica a distintas iniciativas desarrolladas en terceros países (ayuda en la elaboración y aplicación de normativa sobre control de armas, asistencia en la elaboración de informes sobre exportación de armas y apoyo a la formación de los responsables de la concesión de licencias de exportación de armas, entre otras iniciativas).

Paralelamente al hecho de que, el 6 de diciembre de 2006, la AGNU aprobase la Resolución $61 / 89^{43}$ que iniciaba el proceso para la redacción de un tratado sobre el comercio de armas hasta que, el 2 de diciembre de 2009, la AGNU decidiese, mediante la Resolución 64/48 que llevaba por título «El Tratado sobre comercio de armas» ${ }^{44}$, la convocatoria para 2012 de una Conferencia relativa al TCA, la UE, junto a las iniciativas vinculadas a la cooperación al desarrollo aludidas y al apoyo a la aplicación de los criterios recogidos en el Código de Conducta en terceros países, ha tenido un papel muy destacado en el desarrollo de distintas iniciativas dirigidas a promover que terceros Estados se involucrasen en el control de las armas convencionales en línea con el contenido del propio TCA. De esta manera, se conseguía también que terceros países tuviesen presente el «criterio humanitario» en el tráfico de armas. Hasta la aprobación, en abril de 2013, por la AGNU del TCA, la UE centró su actuación en financiar distintos seminarios de expertos gubernamentales que tenían como objetivo facilitar la conclusión de las negociaciones y la futura aplicación del TCA. Mediante la financiación de este tipo de iniciativas se pretendía desarrollar y mejorar «[...] las competencias técnicas a nivel nacional y regional con el objetivo de poner en marcha controles efec-

40 Acción común 2008/230/PESC del Consejo, de 17 de marzo, relativa al respaldo de las actividades de la UE destinadas a fomentar el control de la exportación de armas y los principios y criterios del Código de Conducta de la UE en materia de exportación de armas entre terceros países (DO L núm. 75, de 18 de marzo de 2008).

41 Decisión 2009/1012/PESC del Consejo, de 22 de diciembre, relativa al respaldo de las actividades de la UE destinadas a fomentar el control de la exportación de armas y los principios y criterios de la Posición común 2008/944/PESC entre terceros países (DO L núm. 348, de 29 de diciembre de 2009).

42 Decisión 2012/711/PESC del Consejo, de 19 de noviembre, relativa al respaldo de las actividades de la UE destinadas a fomentar, entre terceros países, el control de la exportación de armas y los principios y criterios de la Posición común 2008/944/PESC (DO L núm. 321, de 20 de noviembre de 2012).

43 A/RES/61/89, de 18 de diciembre de 2006, titulada "Hacia un tratado sobre el comercio de armas: establecimiento de normas internacionales comunes para la importación, exportación y transferencia de armar convencionales».

$44 \mathrm{~A} / \mathrm{RES} / 64 / 48$, de 12 de enero de 2010. 
tivos de las exportaciones y transferencias de armas» ${ }^{45}$ y el refuerzo de «[... $]$ los controles de la transferencia de armas en terceros países ${ }^{46}$.

Una vez aprobado, el 2 de abril de 2013, el TCA por la AGNU, la UE intensificó su estrategia dirigida a promover la pronta entrada en vigor del TCA y su aplicación. En relación con la aplicación por terceros países del criterio humanitario recogido en los arts. 6 y 7 del TCA, se adoptó la Decisión 2013/768/ PESC, de 16 de diciembre ${ }^{47}$, que preveía la posibilidad de financiar proyectos dirigidos a «[...] ayudar a los países beneficiarios a la hora de elaborar, actualizar y en su caso aplicar las medidas legislativas y administrativas pertinentes destinadas a establecer y desarrollar un sistema eficaz para el control de las transferencias de armas, conforme a los requisitos del TCA». De forma implícita, el criterio humanitario parecía informar la elaboración y aplicación de la normativa sobre control del tráfico de armas por terceros países.

Junto a estas iniciativas de apoyo financiero, el Parlamento europeo ha propuesto que el Servicio Europeo de Acción Exterior (SEAE) «[...] incluya entre sus objetivos de política exterior, y entre los temas que deben formar parte de los acuerdos bilaterales, una invitación a los terceros países a adherirse al TCA» ${ }^{48}$ y pide a la Comisión Europea que «[...] estudie en qué medida se pueden utilizar los instrumentos comerciales actuales y futuros para promover la ratificación y aplicación del TCA» ${ }^{49}$. Esta última cuestión ya fue planteada en 2013 por la propia Comisión Europea en un documento de reflexión sobre las armas de fuego y la seguridad interna de la UE al fijar como prioridad del control de las armas ligeras el reforzamiento de la acción exterior en este ámbito. Por ello, señalaba que «la UE continuará incluyendo disposiciones sobre el control de las armas ligeras y de pequeño calibre en todos los acuerdos internacionales pertinentes y continuará racionalizando las medidas relativas a dichos tipos de armas mediante sus instrumentos de cooperación geográfica y temática ${ }^{50}$.

45 Decisión 2010/336/PESC del Consejo, de 14 de junio, relativa a las actividades de la UE en apoyo del Tratado sobre el Comercio de Armas, en el marco de la Estrategia Europea de Seguridad (DO L núm. 152, de 18 de junio de 2010).

46 Decisión 2013/43/PESC del Consejo, de 22 de marzo, sobre el mantenimiento de las actividades de la Unión en apoyo de las negociaciones del Tratado sobre Comercio de Armas, en el marco de la Estrategia Europea de Seguridad (DO L núm. 20, de 23 de enero de 2013).

47 Decisión 2013/768/PESC del Consejo, de 16 de diciembre, sobre las actividades de la UE en apoyo de la aplicación del Tratado sobre el Comercio de Armas, en el marco de la Estrategia europea de seguridad (DO L núm. 341, de 18 de diciembre de 2013).

48 «Resolución del Parlamento Europeo sobre la ratificación del Tratado sobre el Comercio de Armas», B7-0075/2014, de 5 de febrero, apartado 2.

49 Ibid., p. 3.

50 «Comunicación de la Comisión al Consejo y al Parlamento Europeo: las armas de fuego y la seguridad interna de la UE: proteger a los ciudadanos e impedir el tráfico ilícito», COM (2013) 716 final, de 21 de octubre, apartado 4.3. A pesar de esta afirmación, lo cierto es que, a fecha de hoy, solo se ha incluido este tipo de cláusula (no referida a las armas ligeras, sino en relación con el compromiso de no promover la proliferación de armas de destrucción masiva) en un Acuerdo comercial celebrado entre la UE y sus Estados miembros con Colombia y Perú (Decisión 735/2012/UE del Consejo, de 31 de mayo, relativa a la firma, en nombre de la Unión, y a la aplicación provisional del Acuerdo comercial entre la Unión Europea y sus Estados miembros, por una parte, y Colombia y el Perú, por otra, en $D O$ L 
Asimismo, al hilo del proceso actual de revisión de la política europea de control de exportaciones de armas de doble uso, la Comisión Europea ha aludido al criterio humanitario como aspecto a tener en cuenta en el rediseño de dicha política. Así, la Comisión, después de «[...] considerar la evolución hacia un enfoque de la "seguridad humana" que reconozca la inextricable vinculación entre la seguridad y los derechos humanos» se plantea llevar a cabo una «[...] aclaración de los criterios de control [de la exportación de armas de doble uso] a fin de tomar en consideración implicaciones de seguridad en un sentido más amplio, incluido el efecto potencial sobre la seguridad de las personas, por ejemplo a través del terrorismo y de las violaciones de los derechos humanos» ${ }^{51}$.

\section{LOS EMBARGOS DE ARMAS ADOPTADOS DE FORMA AUTÓNOMA POR LA UNIÓN EUROPEA COMO VÍA PARA PREVENIR LAS VIOLACIONES DE LOS DERECHOS HUMANOS}

Si bien es cierto que, conforme al art. 346 del TFUE, los Estados miembros tienen competencia exclusiva en lo relativo a la "producción o al comercio de armas, municiones y material de guerra» y que a ellos les corresponde aplicar el criterio humanitario recogido en las distintas disposiciones adoptadas por la UE ya analizadas y posteriormente recogido en sus disposiciones nacionales, la UE ha adoptado, al amparo del art. 215 del TFUE, medidas restrictivas contra terceros países que han consistido en la prohibición de que los Estados miembros vendan armas convencionales o suministren asistencia técnica y financiera y otros equipos relacionados con el equipo militar que puedan utilizarse "con fines de represión interna».

Del análisis de las distintas disposiciones de política exterior que suponen la adopción de medidas restrictivas en este ámbito se observa que la UE no alude de forma expresa a las violaciones de los derechos humanos como motivo para decretar embargos de armas contra terceros países, sino que vincula la aplicación y vigencia del criterio humanitario a la utilización de las armas y equipos militares «con fines de represión interna». El Código de Conducta en materia de exportación de armas aprobado por el Consejo de Asuntos Generales el 25 de mayo de 1998 recogía el respeto de los derechos humanos en el país de destino final de las armas como segundo criterio para no expedir licencias de exportación, precisando dicho concepto al considerar por represión interna «[...] la tortura y otros tratos o sanciones crueles, inhumanos y degradantes, las ejecuciones sumarias o arbitrarias, las desapariciones, las detenciones arbitrarias y toda violación de los derechos humanos y de las libertades fundamentales como se definen en los instrumentos

núm. 354, de 21 de diciembre de 2012. El art. 2 del acuerdo lleva por título «Desarme y no proliferación de armas de destrucción masiva»).

51 «Comunicación de la Comisión al Consejo y al Parlamento Europeo: Revisión de la política de control de las exportaciones: garantizar la seguridad y la competitividad en un mundo cambiante», COM (2014) 244 final, de 24 de abril, p. 6. 
internacionales pertinentes de derechos humanos, incluida la Declaración Universal de Derechos Humanos y el Pacto Internacional de Derechos Civiles y Políticos» ${ }^{52}$. Este concepto fue reiterado posteriormente por la Guía de usuario, que precisaba distintas nociones relacionadas con el control de las exportaciones de tecnología y equipos militares e introducía como novedad un conjunto de pautas a la hora de que los Estados valorasen si la exportación de armas propuesta podía utilizarse para la represión interna. Estas pautas estaban esencialmente relacionadas con el grado de tutela y observancia de los derechos humanos en el país receptor de las armas ${ }^{53}$.

En todo caso, al margen de la inserción en las normas sobre control de exportaciones de armas de los distintos Estados miembros (entre ellos, como hemos visto, España) del criterio humanitario vinculado al hecho de que las armas se utilicen para fines de represión interna, lo cierto es que la UE ha recurrido también a esta terminología a la hora de adoptar embargos de armas. Del análisis de los distintos embargos que se han decretado aplicando el criterio humanitario se desprende que estos han sido adoptados, en la práctica mayoría de los casos, cuando los embargos de armas han sido decididos de forma autónoma por la UE y no en cumplimiento de Resoluciones del Consejo de Seguridad (CS).

En los embargos de armas adoptados de forma unilateral por la UE, que no se vinculan necesariamente a la existencia de un conflicto armado interno ${ }^{54}$, se prohíbe la venta, transferencia o exportación de distintos equipos que se enumeran en un anexo al reglamento que sirve para adoptar medidas restrictivas contra un determinado Estado al considerarse que estos equipos (armas de fuego, munición, bombas y granadas, determinados vehículos, cargas explosivas, cascos, cuchillos y simuladores, entre otros) pueden «[...] utilizarse con fines de represión interna».

Distintos ejemplos de la práctica reciente ponen de relieve la preocupación de la UE por el hecho de que las armas que se vendan a determina-

52 Sesión núm. 2097 del Consejo, Doc. 8687/98, de 25 de mayo.

53 Así, se señalaba «[...] que los Estados miembros tendrán en cuenta los antecedentes del usuario final propuesto en materia de derechos humanos y los del país receptor en general. Respecto del país receptor se tendrán en cuenta las directrices de actuación del gobierno de dicho país, los aspectos significativos de su evolución reciente, incluidos, entre otros, el impacto de la "lucha contra el terrorismo", la existencia de una tutela efectiva de los derechos humanos en su constitución, la formación en materia de derechos humanos entre los actores clave (por ejemplo, los servicios policiales), la impunidad de las violaciones de los derechos humanos, la existencia de órganos de control independientes y de entidades nacionales de fomento o protección de los derechos humanos». Véase «Guía del usuario de la Posición común 2008/944/PESC del Consejo por la que se definen las normas comunes que rigen el control de las exportaciones de tecnología y equipos militares», Doc. 9241/09, de 29 de abril, p. 39.

54 El Consejo de Derechos Humanos ha aludido a esta vertiente de los embargos de armas en su Resolución de 8 de octubre de 2013 relativa a las «Repercusiones de las transferencias de armas en los derechos humanos durante los conflictos armados» en la cual se «insta a todos los Estados a abstenerse de transferir armas a los que participen en conflictos armados cuando dichos Estados consideren, con arreglo a sus procedimientos nacionales aplicables y a las obligaciones y normas internacionales que les incumben, que es bastante probable que esas armas puedan emplearse para cometer o facilitar violaciones o vulneraciones graves del Derecho internacional de los derechos humanos o del Derecho internacional humanitario». Véase A/HRC/RES/24/35, apartado 3. 
dos países puedan ser utilizadas para cometer violaciones de los derechos humanos y, por ello, decreta el embargo de determinados equipos sin que exista ninguna resolución del CS. Así, a modo de ejemplo, cabe aludir a las medidas restrictivas adoptadas en 2009 contra la República de Guinea como respuesta a la violenta represión ejercida el 28 de septiembre de 2009 por las fuerzas y cuerpos de seguridad en Conakry contra los participantes en una manifestación política donde se produjeron abusos en materia de derechos humanos. Al entender que los hechos eran graves, la UE consideró necesario adoptar medidas contra «[...] los miembros del Consejo Nacional para la Democracia y el Desarrollo y personas asociadas con ellos, responsables de la violenta represión o del bloqueo político del país e imponer un embargo de armas contra la República de Guinea» ${ }^{55}$ y, por ello, prohibió «[...] vender, suministrar, transferir o exportar, de forma directa o indirecta, equipos que puedan utilizarse con fines de represión interna a cualquier persona física o jurídica o a cualquier entidad u organismo de la República de Guinea, o para su uso en la República de Guinea, tanto si dichos equipos son originarios de la Unión como si no lo son» ${ }^{56}$. La lista de equipos que podían utilizarse con fines de represión interna figuraban en un anexo al Reglamento que decretaba las medidas restrictivas.

Supuesto idéntico se ha planteado en relación con el conflicto armado que se vive actualmente en Siria. Si bien el CS ha condenado enérgicamente «[...] las violaciones generalizadas de los derechos humanos y del Derecho internacional humanitario cometidas por las autoridades sirias» ${ }^{57} \mathrm{y}$ ha aludido únicamente a la existencia de armas químicas en el conflicto y ha adoptado medidas para evitar su almacenamiento y utilización por Siria y por otros agentes no estatales ${ }^{58}$, no ha adoptado ningún tipo de medida restrictiva vinculada a la violación de los derechos humanos de la población civil por la utilización de armas contra esta. Así, y como respuesta a la «[...] violenta represión, incluso con fuego real, contra protestas pacíficas en diversas localidades de toda Siria que produjo la muerte de varios manifestantes, heridos y detenciones arbitrarias», la UE adoptó distintas medidas restrictivas contra Siria y contra las personas responsables de la represión violenta ejercida contra la población civil de Siria, que se concretaron en la prohibición de vender, suministrar o transferir equipos que pudieran utilizarse para la represión interna $^{59}$.

55 Posición común 2009/788/PESC del Consejo, de 27 de octubre, relativa a la adopción de medidas restrictivas contra la República de Guinea (DO L núm. 281, de 28 de octubre de 2009).

56 Véase el art. 2 del Reglamento 1284/2009 del Consejo, de 22 de diciembre, por el que se imponen determinadas medidas restrictivas contra la República de Guinea ( $D O$ L núm. 280, de 26 de octubre de 2010).

57 Resolución 2139 (2014), de 22 de febrero [S/RES/2139 (2014), apdo. 1, p. 3].

58 Véase Resolución 2118 (2013), de 27 de septiembre [S/RES/2118 (2013)] y Resolución 2209 (2015), de 6 de marzo [S/RES/2209 (2015)].

59 Véase Decisión 2011/273/PESC del Consejo, de 9 de mayo, relativa a la adopción de medidas restrictivas contra Siria (DO L núm. 121, de 10 de mayo de 2011) y Reglamento 442/2011 del Consejo, de 9 de mayo, relativo a las medidas restrictivas habida cuenta de la situación en Siria (DO L núm. 121, de 10 de mayo de 2011). 
Las medidas restrictivas adoptadas de forma autónoma por la UE contra Zimbabue ${ }^{60}$ y Bielorrusia ${ }^{61}$ reproducen el esquema visto en relación con Guinea y Siria y constituyen dos ejemplos más de la prohibición específica de vender equipos y armas que puedan utilizarse para reprimir a la población. Junto a estas medidas adoptadas formalmente, la UE ha adoptado informalmente (pues no se han concretado en Decisiones y Reglamentos) embargos de equipos militares a Egipto y Ucrania para evitar que puedan ser utilizados con fines de represión interna. Así, en el Consejo de Asuntos Exteriores de 21 de agosto de 2013 se acordó que los Estados suspenderían «[...] las licencias de exportación a Egipto de todo material que pudiera utilizarse para la represión interna $[. .$.$] » y que se "reconsiderarían [...] las licencias de exportación$ de los equipos a que se refiere la Posición Común 2008/944/PESC, además de reexaminar su asistencia de su seguridad a Egipto» ${ }^{62}$. Lo mismo sucedió en relación con la imposición informal de sanciones contra los responsables de la violencia y el uso excesivo de la fuerza en Ucrania adoptadas por el Consejo de Asuntos Exteriores de 20 de febrero de 2014. En dicho Consejo, los Estados miembros acordaron suspender las licencias de exportación de equipo militar que pudieran utilizarse para la represión interna de la población ucraniana ${ }^{63}$.

Paralelamente a estas consideraciones humanitarias en las medidas restrictivas adoptadas autónomamente por la UE, en algún supuesto la UE ha decretado un embargo de armas dando cumplimiento a una Resolución del CS y ha incluido, a falta de una referencia expresa por parte del CS, una alusión al criterio humanitario. Así, el 15 de noviembre de 2004, el CS adoptó la Resolución 1572 (2004) relativa a la situación en Costa de Marfil en virtud de la cual todos los Estados debían adoptar «[...] las medidas necesarias para impedir que, de forma directa o indirecta, se suministren, vendan o transfieran a Côte d'Ivoire, desde sus territorios o por sus nacionales, o utilizando buques o aeronaves de su pabellón, armamentos o cualquier material conexo, en particular aeronaves militares y equipo, independientemente de que procedan o no de sus territorios, o que se ofrezca cualquier tipo de asistencia, asesoramiento o capacitación en relación con actividades militares» ${ }^{64}$. Para dar cumplimiento a esta resolución, se adoptó la Posición común 2004/852/ PESC del Consejo, de 13 de diciembre, relativa a la adopción de medidas restrictivas contra Costa de Marfil ${ }^{65}$ y, en ella, la UE, junto a un embargo de

60 Véase, en este sentido, el art. 2 de la Posición común 2002/145/PESC del Consejo, de 18 de febrero, relativa a la adopción de medidas restrictivas contra Zimbabue ( $D O$ L núm. 50, de 21 de febrero de 2002) y el art. 7 del Reglamento 310/2002 del Consejo, de 18 de febrero, relativo a determinadas medidas restrictivas respecto de Zimbabue ( $D O$ L núm. 50, de 21 de febrero de 2002).

${ }_{61}$ Véase, en este sentido, el art. 1 de la Decisión 2011/357/PESC del Consejo, de 20 de junio, relativa a la adopción de medidas restrictivas contra determinados funcionarios de Bielorrusia (DO L núm. 161, de 21 de junio de 2011) y el art. 1 del Reglamento 588/2011 del Consejo, de 20 de junio, relativo a la adopción de medidas restrictivas contra el Presidente Lukashenko y determinados funcionarios de Bielorrusia (DO L núm. 161, de 21 de junio de 2011).

62 Sesión núm. 3256 del Consejo de Asuntos Exteriores, Doc. 13086, de 21 de agosto de 2013, p. 7.

${ }^{63}$ Sesión núm. 3300 del Consejo de Asuntos Exteriores, Doc. 6767/14, de 20 de febrero de 2014.

64 S/RES/1572 (2014), apartado 7.

65 DO L núm. 368, de 15 de diciembre de 2004. 
armas, decretaba la prohibición de que los Estados miembros vendiesen o suministrasen a dicho país equipos que pudieran utilizarse con fines de represión interna ${ }^{66}$.

Las medidas restrictivas decretadas por el CS habida cuenta de la situación en Libia y su ejecución por parte de la UE constituyen otro ejemplo de la inserción del criterio humanitario en los embargos de armas decretados por la Unión sin una referencia previa en la Resolución del CS que impone el embargo de armas. Así, en la Resolución 1970 (2011), de 26 de febrero, el CS decreta, entre otras medidas, un embargo de armas a la Jamahiriya Árabe Libia que afecta la venta, suministro o transferencia de «[...] armas y municiones, vehículos y equipo militares, equipo paramilitar y piezas de repuesto $[\ldots]]^{67}$, pero no se alude a los efectos que su utilización puede tener sobre los derechos humanos de la población civil ${ }^{68}$. Para ejecutar esta resolución, la UE adoptó el Reglamento 204/2001 del Consejo, de 2 de marzo, relativo a las medidas restrictivas habida cuenta de la situación en Libia en el cual se prohibía «[...] vender, suministrar, transferir o exportar, consciente y deliberadamente, el equipo destinado a la represión interna [...] ${ }^{69}$ que se relacionaba en un anexo al mismo.

De la práctica sancionadora decretada por la UE se deduce una especial sensibilidad en relación con el uso final que se puede hacer de determinados equipos en términos de derechos humanos y, por ello, junto a los embargos de armas genéricos que se decretan, se prohíbe de forma específica la venta o suministro de determinadas armas y otros artefactos que puedan utilizarse contra la población civil. Ello entra en coherencia con las pautas definidas por la UE en relación con el comercio de armas recogidas en el Código de Conducta de 1998 y seguramente explica la referencia al criterio humanitario tanto si las medidas restrictivas son adoptadas autónomamente como si son al amparo de resoluciones del CS. Ello entronca con el hecho de que la UE «[...] cuenta con un marco jurídicamente vinculante, único en el mundo, que mejora el control de las exportaciones de armas, en particular en las regiones en crisis y en países que presentan unos resultados deficientes en materia de derechos humanos $[\ldots]_{»^{70}}$.

${ }^{66}$ La imposición de embargos de armas a Costa de Marfil por el CS y su ejecución por la UE con una clara referencia al criterio humanitario se ha mantenido en todas las resoluciones del CS y en las decisiones y reglamentos adoptados por la UE. La última manifestación lo constituye la Resolución 2153 (2014), de 29 de abril, del CS [S/RES/2153 (2014)] sobre la situación en Costa de Marfil y la Decisión 2014/460/PESC del Consejo por la que se renuevan las medidas restrictivas contra Costa de Marfil (DO L núm. 207, de 15 de julio de 2014).

67 S/RES/1970 (2011), apartado 9.

68 Llama la atención que en el apartado 14 de la Resolución el CS solicite a los Estados que adopten las medidas necesarias para disuadir a nacionales suyos a viajar a dicho país «[...] para participar en actividades, en nombre de las autoridades libias, de las que pueda pensarse razonablemente que habrán de contribuir a la violación de los derechos humanos».

69 Art. 2.1 del Reglamento (DO L núm. 58, de 3 de marzo de 2011).

70 «Propuesta de resolución común del Parlamento europeo sobre las exportaciones de armamento: aplicación de la Posición común 2008/944/PESC», B7-0260/2013, de 2 de julio, apartado H.1. 


\section{DE LA TEORÍA A LA PRÁCTICA: LA APLICACIÓN DEL CRITERIO HUMANITARIO POR ESPAÑA}

Como se ha visto, la UE ha desarrollado un marco jurídico en materia de comercio de armas en el cual, ya antes de que el TCA recogiese el criterio humanitario en su articulado, se pone de manifiesto su preocupación por que las armas que los Estados vendan a terceros países no sean utilizadas contra la población civil. La cuestión que cabe plantearse es cuál ha sido la virtualidad práctica del criterio humanitario y, por ello, analizaremos la práctica desarrollada por España en este ámbito. Dicho análisis se hará sobre la base de la única información disponible al efecto, que es la que se desprende de la comparecencia anual que, al amparo del art. 16.2 de la Ley 53/2007 ${ }^{71}$, hace el secretario de Estado de Comercio ante la Comisión de Defensa del Congreso de los Diputados para presentar las estadísticas españolas de exportación de material de defensa, de otro material y de los productos y tecnologías de doble uso.

El primer problema que plantea la aplicación práctica del criterio humanitario reside en la falta de transparencia a la hora de conocer las licencias de exportación de armas que se conceden. Ciertamente, tanto la legislación de la UE sobre comercio de armas (incluidos los embargos de armas que se puedan decretar) como la legislación española aluden claramente a que no se podrán autorizar ventas de armas a aquellos países que las puedan utilizar para cometer violaciones de los derechos humanos. La decisión final de exportar armas no es de la UE, sino de cada Estado miembro y, por ello, cabe preguntarse cómo se conceden dichas licencias.

En el caso español, conforme al art. 14 de la Ley 53/2007, las licencias de exportación de armas las concede la Junta Interministerial Reguladora del Comercio Exterior de Material de Defensa y de Doble Uso (JIMDDU) y sus actas, conforme a un acuerdo del Consejo de Ministros de 13 de marzo de 1987 adoptado al amparo de la Ley 9/1968, de 5 de abril, sobre Secretos Oficiales ${ }^{72}$, son secretas. En las actas de la JIMDDU se recogen todos los datos/información que lleva a dicho organismo a otorgar o no una licencia de exportación a un determinado país, pero al poseer un carácter confidencial se hace muy difícil conocer si el criterio humanitario es utilizado como criterio efectivo en la concesión de licencias ${ }^{73}$.

El hecho de que la aplicación del criterio humanitario (uno más entre los ocho recogidos en la Posición común 2008/944/PESC del Consejo, de 8 de diciembre, por la que se definen las normas comunes que rigen el control de

${ }^{71}$ Ley 53/2007, de 28 de diciembre, sobre el control del comercio exterior de material de defensa y de doble uso (BOE núm. 312, de 29 de diciembre de 2007).

72 BOE de 6 de abril de 1968.

73 Véase Melero Alonso, E., «El secreto oficial en las ventas de armas. Un supuesto de aplicación ilegal de la Ley sobre Secretos Oficiales (Las razones por las que los datos de las exportaciones de armas deben hacerse públicos)», Revista de Administración Pública, 2000, núm. 152, pp. 229-267. Del mismo autor, véase Régimen jurídico del control de las exportaciones de material de defensa y de doble uso. El secreto negocio de la industria de guerra, Madrid, Dykinson, 2008, passim. 
las exportaciones de tecnología y equipos militares) descanse sobre la libre apreciación no sujeta a control ni a transparencia de la JIMDDU que avala una de las críticas hechas por el Parlamento Europeo a dichos criterios que es la relativa a que «[...] los ocho criterios se aplican e interpretan con rigurosidad variable en los Estados miembros de la UE [...]» ${ }^{74}$. Ello ciertamente está vinculado a que las licencias de exportación las conceden los Estados (y no la UE al carecer esta de competencia sobre la materia), los cuales, como España, alegan motivos seguridad y de política exterior, para no hacer públicos los motivos que llevan a la JIMDDU a tomar una decisión ${ }^{75}$. La falta de transparencia hace que sea imposible saber con exactitud el grado de observancia del criterio humanitario por parte del Gobierno español en su política de venta de armas. Ello todavía es más grave si se tiene en cuenta que España ocupa, dentro de la UE, el cuarto lugar en ventas de armas a terceros países ${ }^{76}$.

Si bien es cierto que la mayoría de ventas de armas tuvieron como destinatarios países de la UE o de la OTAN, resulta destacable, como ha puesto de relieve el secretario de Estado de Comercio en su último informe sobre la venta de armas presentado en 2014 ante la Comisión de Defensa del Congreso de los Diputados, que España vendió armas a 41 países no miembros de la UE y de la OTAN, siendo Emiratos Árabes Unidos, Australia y Arabia Saudí los principales compradores ${ }^{77}$. Del análisis detallado de esta comparecencia llama la atención que el criterio humanitario solo sirvió para no autorizar la venta de siete pistolas a Egipto ante «[...] el riesgo de uso en posibles actos de violación de los derechos humanos [...]» ${ }^{78}$, que, además, era consecuencia de la aplicación del embargo informal decretado por el Consejo de Asuntos Exteriores de la Unión de 21 de agosto de 2013. En la anterior comparecencia del secretario de Estado de Comercio ante la Comisión de Defensa en 2013 señaló que España había suministrado armas a un total de 42 países no miembros de la UE o de la OTAN y que ninguna de las licencias se denegó como consecuencia de la aplicación del criterio humanitario ${ }^{79}$. En 2013 el volumen de ventas de armas autorizadas por España fue similar al de 2014.

\footnotetext{
74 «Propuesta de resolución común del Parlamento europeo sobre las exportaciones de armamento: aplicación de la Posición común 2008/944/PESC», B7-0260/2013, de 2 de julio, apartado H.1.

75 En este sentido, resulta muy elocuente (y criticable) la afirmación hecha en relación con esta cuestión por el secretario de Estado de Comercio en la comparecencia del 16 de junio de 2014 ante la Comisión de Defensa del Congreso de los Diputados para informar acerca de las estadísticas españolas sobre exportación de armas según la cual «[...] creo que es razonable que los criterios sean públicos pero que las decisiones que llevan a la aplicación de esos criterios y que pueden llevar a revocar una decisión no sean públicos, entre otras cosas porque se estarían revelando probablemente fuentes de información del Estado o se estarían revelando valoraciones que hace el Estado sobre las situaciones en determinados países, cosa que podría llegar a ser contraproducente desde el punto de vista de la política exterior». Véase Diario de Sesiones del Congreso de los Diputados, Comisiones, X Legislatura, núm. 590, de 16 de junio de 2014, p. 19.

76 SIPRI Yearbook 2015. Armaments, Disarmament and International Security, p. 17.

77 Diario de Sesiones del Congreso de los Diputados, Comisiones, X Legislatura, núm. 590, de 16 de junio de 2014, p. 2.

78 Ibid., p. 3.

79 Comparecencia del secretario de Estado de Comercio ante la Comisión de Defensa del Congreso de los Diputados para presentar las estadísticas españolas de exportación de material de defensa, de
} 
Junto a la falta de transparencia, otra crítica que se ha hecho en relación con las autorizaciones de ventas de armas es que, como señala el Parlamento Europeo, el control del cumplimiento de los criterios se realiza de conformidad con las reglamentaciones nacionales lo que hace imposible controlar de forma independiente el cumplimiento de los ocho criterios ${ }^{80}$. Asimismo, «[...] el incumplimiento de los ocho criterios por parte de un Estado miembro no tiene consecuencias» ${ }^{81}$. En el caso español, ciertamente el marco legal y reglamentario sobre la venta de armas tiene en cuenta el criterio humanitario, pero resulta prácticamente imposible determinar si este se aplica o no dada la opacidad con que la JIMDDU concede las licencias de exportación.

Con un volumen tan elevado de exportación de armas por parte de España a más de 40 países (entre los que destacan Emiratos Árabes Unidos, Arabia Saudí, Baréin, Catar, Colombia, Ucrania, Venezuela, Ghana o Egipto) resulta poco creíble que la aplicación del criterio humanitario solo haya servido para no autorizar, en 2013, la venta de siete pistolas a Egipto. Esta opacidad hace que sea muy difícil determinar si España cumple o no los criterios fijados por la UE y recogidos posteriormente en nuestra legislación sobre comercio de armas. Lo mismo se puede decir en relación con los embargos de armas decretados por la UE. Esta opacidad dificulta el control que puedan hacer los órganos jurisdiccionales españoles de las decisiones adoptadas por la JIMDDU y por los distintos poderes públicos involucrados en la venta de armas sobre la base de las eventuales denuncias presentadas por particulares o por entidades no gubernamentales preocupadas por estas cuestiones.

\section{CONSIDERACIONES FINALES}

Ciertamente, la entrada en vigor, el pasado 24 de diciembre de 2014, del TCA, supone un avance muy relevante en la regulación y control del tráfico mundial de armas convencionales y en el reconocimiento por parte de la comunidad internacional de que los Estados no pueden vender armas cuando se tenga constancia de que estas puedan ser utilizadas para cometer violaciones graves de los derechos humanos. La UE, y particularmente España al ser uno de los pocos países que aplicó provisionalmente las disposiciones del TCA que recogen el criterio humanitario antes de que dicho tratado entrase en vigor, ha reconocido en su normativa la relevancia de los derechos humanos como criterio para no conceder licencias de exportación de armas y ha proyectado dicho criterio en distintas iniciativas vinculadas a la acción exterior de la UE. Ello manifiesta un claro compromiso de la UE con la seguridad

otro material y de productos y tecnologías de doble uso celebrada el 5 de junio de 2013. Véase Diario de Sesiones del Congreso de los Diputados, Comisiones, X Legislatura, núm. 335, de 5 de junio de 2013, p. 3.

80 «Propuesta de resolución común del Parlamento europeo sobre las exportaciones de armamento: aplicación de la Posición común 2008/944/PESC», B7-0260/2013, de 2 de julio, apartado M.7, p. 5.

81 Ibid. 
humana al pretender que las personas que habiten en terceros países puedan vivir de forma segura y sin violencia.

Especialmente destacable resulta que tanto la normativa adoptada por la UE y su traslación en el ámbito nacional, como las distintas iniciativas desarrolladas por aquella en materia de política exterior relacionadas con la venta de armas no exigen un plus específico en la violación de los derechos humanos como sí exige el TCA al referirse a las violaciones graves del DIDH, del DIH o la comisión de un crimen grave de trascendencia internacional. De esta manera, el mero hecho de que las armas que los Estados vendan a terceros países puedan ser utilizadas para la represión interna, a la que se vincula la violación de los derechos humanos, implica la no concesión de licencias de exportación sin que sea necesario una especial gravedad en la violación de los derechos humanos de la población civil.

Al margen de las disposiciones internas que, auspiciadas por la UE, han adoptado los Estados aludiendo al criterio humanitario como límite a la exportación de armas y que constituyen un avance muy relevante incluso antes del reconocimiento en el TCA del criterio humanitario, la UE ha desarrollado distintas iniciativas relacionadas con el comercio de armas a terceros países en los cuales el respeto de los derechos humanos está muy presente. Ello constituye otro ejemplo del compromiso formal de la UE en la promoción exterior de los derechos humanos.

Ahora bien, la aplicación por los Estados, especialmente de España, del criterio humanitario a la hora de conceder licencias de exportación de armas no es muy satisfactoria. En nuestro caso, el secretismo y la falta de transparencia de la JIMDDU hace muy difícil saber si España realmente cumple con los embargos adoptados por el CS y por la UE y con lo dispuesto en la normativa española sobre comercio de armas. Teniendo en cuenta el gran volumen de armas que exporta España y los países destinatarios de las mismas, resulta poco convincente y criticable la mínima aplicación que el criterio humanitario ha tenido.

\author{
RESUMEN \\ POLÍTICA EUROPEA DE CONTROL DE LAS EXPORTACIONES DE ARMAS \\ CONVENCIONALES Y SEGURIDAD HUMANA: MECANISMOS PARA FOMENTAR \\ EL RESPETO DE LOS DERECHOS HUMANOS
}

Partiendo del análisis de la incorporación del criterio humanitario (limitaciones a la venta de armas convencionales que puedan utilizarse para cometer violaciones de los derechos humanos) con anterioridad a la entrada en vigor del Tratado sobre el Comercio de Armas en la normativa europea de exportación de armas y su proyección en las legislaciones nacionales (especialmente, España), este estudio pretende analizar distintos instrumentos de política exterior como la cooperación al desarrollo o los embargos decretados de forma unilateral que ha utilizado la UE para evitar que las armas que los países miembros vendan a terceros Estados puedan ser utilizados contra la población civil, valorándose en último término la práctica desarrollada por España en materia de venta de armas en relación con la observancia del criterio humanitario. 
Palabras clave: Tratado sobre el Comercio de Armas, política europea de exportación de armas convencionales, derechos humanos, tráfico de armas, política española de exportación de armas convencionales.

\section{ABSTRACT \\ EUROPEAN POLICY OF CONTROL OF EXPORTS OF CONVENTIONAL ARMS AND HUMAN SECURITY: MECHANISMS TO PROMOTE RESPECT FOR HUMAN RIGHTS}

Based on the analysis of the incorporation of humanitarian criteria (limitations on the sale of conventional weapons that can be used to commit violations of human rights) prior to the entry into force of the Treaty on Arms Trade in the European arms export policy and its projection in national (especially Spain) legislation, this study aims at analysing various instruments of foreign policy, such as development cooperation or unilaterally imposed embargoes, that the EU has used to prevent Member States from selling arms that can be used against civilians to third countries. Ultimately, the study examines the Spanish practice developed on arms sales in connection with the observance of humanitarian criteria.

Keywords: Treaty on Arms Trade, European conventional arms export policy, Human rights, Arms trafficking, Spanish conventional arms export policy.

\section{RÉSUMÉ}

\section{POLITIQUE EUROPÉENNE DE CONTRÔLE DES EXPORTATIONS DES ARMES CONVENTIONNELLES ET SÉCURITÉ HUMAINE: MÉCANISMES POUR PROMOUVOIR LE RESPECT DES DROITS HUMAINS}

Basée sur l'examen de l'incorporation du critère humanitaire (limitations sur la vente d'armes conventionnelles qui pourraient être utilisées pour commettre des violations des droits humains) avant l'entrée en vigueur du Traité sur le Commerce des Armes dans la réglementation européenne d'exportation des armes et sa projection dans la législation nationale (notamment, l'Espagne), cette étude vise à analyser les différents instruments de politique extérieure (comme la coopération au développement ou les embargos imposés unilatéralement) utilisés par l'UE pour empêcher l'utilisation d'armes en provenance des pays membres contre des personnes civiles. À la fin du travail on fait une évaluation de la pratique développée par l'Espagne sur les ventes d'armes dans le cadre du respect du critère humanitaire.

Mots-clés: Traité sur le Commerce des Armes, Politique européenne d'exportation des armes conventionnelles, Droits de l'homme, Trafic d'armes, Politique espagnole d'exportation d'armes conventionnelles. 